Maria Augusta Amaral Campos a Ana Paula Salles Moura Fernandes a Leiliane Coelho André ${ }^{a}$

\section{Avaliação da exposição ocupacional ao benzeno em trabalhadores frentistas e analistas de combustíveis utilizando o Teste Cometa como biomarcador de genotoxicidade}

\author{
Comet assay as a biomarker of genotoxicity to assess occupational \\ exposure to benzene in gas-station attendants and fuel analysts
}

a Universidade Federal de Minas Gerais, Faculdade de Farmácia, Departamento de Análises Clínicas e Toxicológicas. Belo Horizonte, MG, Brasil.

Contato:

Leiliane Coelho André

E-mail:

leiliane@ufmg.br

O trabalho foi subvencionado com recursos provenientes do Ministério da Saúde, por meio do Termo de Cooperação FNS 181/2012.

Os autores declaram não haver conflitos de interesses

O trabalho foi baseado em dissertação de Maria Augusta Amaral Campos, intitulada "Teste cometa: validação do método e avaliação da exposição ocupacional ao benzeno presente na gasolina através dos biomarcadores de exposição e genotoxicidade", defendida em 2013 no programa de Pós-Graduação em Ciências Farmacêuticas da Faculdade de Farmácia da Universidade Federal de Minas Gerais.

O trabalho foi apresentado no II Encontro Ibero-Americano de Toxicologia e Saúde Ambiental, Ribeirão Preto, 2013, e publicado nos anais na forma de resumo, intitulado "Assessment of occupational exposure to benzene by the exposure biomarker and comet assay in workers exposed to gasoline".

Recebido: 15/06/2015

Revisado: 19/07/2016

Aprovado: 02/08/2016

\section{Resumo}

Introdução: frentistas e analistas de combustíveis estão expostos a vários compostos orgânicos voláteis presentes na gasolina, incluindo benzeno, que se destaca por sua importância toxicológica. Objetivo: avaliar a exposição ocupacional ao benzeno na gasolina, utilizando o Teste Cometa como biomarcador de genotoxicidade em comparação ao ácido trans,trans-mucônico urinário (AttM) como biomarcador de exposição ao benzeno. Métodos: estudo de corte transversal com análises de biomarcadores de exposição e de genotoxicidade em grupo de expostos ocupacionalmente ao benzeno através da gasolina e grupo controle. Resultados: o Teste Cometa mostrou uma média (desvio padrão) de índice de dano, expresso em unidades arbitrárias, no grupo exposto de 28,4 (10,1) significativamente mais elevado do que no grupo não-exposto, $18,4(10,1)$. O AttM urinário, em mg/g de creatinina, foi significativamente maior no grupo exposto, 1,13 $(0,45)$, em relação ao grupo não exposto, 0,44 $(0,33)$. Os dois biomarcadores apresentaram boa correlação linear $(\mathrm{r}=0,81 ; \mathrm{p}<0,05)$, indicando uma forte associação entre o biomarcador de exposição e o biomarcador de efeito. Conclusão: os resultados sugerem que uma maior exposição ocupacional ao benzeno está associada a um risco aumentado de dano genotóxico entre indivíduos expostos à gasolina.

Palavras-chave: benzeno; exposição ocupacional; Teste Cometa; ácido trans,trans-mucônico.

\begin{abstract}
Introduction: gas-station attendants and fuel analysts are exposed to various volatile organic compounds found in gasoline, including benzene, which stands out because of its toxicological significance. Objective: to assess occupational exposure to benzene using the comet assay as a biomarker of genotoxicity in comparison to the urinary trans, trans muconic acid (ttMA) as benzene exposure biomarker. Methods: cross-sectional study using biomarkers of exposure and genotoxicity analyses in a group of workers occupationally exposed to benzene from gasoline compared with a control group. Results: the comet assay results showed that the mean (standard deviation) damage index, in arbitrary units, in the exposed group, 28.4 (10.1), was significantly higher than in the non-exposed group, 18.4 (10.1). The mean value of urinary ttMA was significantly higher in the exposed group, 1.13 (0.45), compared to the non-exposed group, 0.44 (0.33). Both biomarkers showed a linear correlation $r=0.81(p<0.05)$ indicating a strong association between the exposure biomarker and the biomarker effect. Conclusion: the results suggest that a greater occupational exposure to benzene is associated to an increased risk of genotoxic damage among individuals exposed to gasoline.
\end{abstract}

Keywords: benzene; occupational exposure; comet assay; trans, trans muconic acid. 


\section{Introdução}

O benzeno é o hidrocarboneto aromático mais tóxico, classificado pela Agência Internacional de Pesquisa em Câncer (IARC), da Organização Mundial da Saúde (OMS), no Grupo I, como cancerígeno para os seres humanos. É encontrado naturalmente no petróleo e na produção de aço como um subproduto na produção de "coque" e em processos de síntese química, onde ocorre a principal exposição ocupacional ao benzeno ${ }^{1}$.

A gasolina é uma importante fonte de exposição ambiental e ocupacional ao benzeno considerando que a substância pode estar presente de 1 a $5 \%$, cujo valor real varia em diferentes países ${ }^{2}$. No Brasil, a Agência Nacional do Petróleo (ANP) estabeleceu por meio da Resolução 40, de 25 de outubro de $2013^{3}$, o valor máximo de concentração de benzeno de $1 \%$ (v/v) na gasolina do tipo $\mathrm{C}$ ou Premium tipo C. Atualmente, as diretrizes dos países da América do Norte e da Europa apontam para redução do benzeno na gasolina para um nível menor que 1\%. A tendência de reduzir o benzeno na gasolina nesses países é devido à necessidade de redução da exposição ocupacional dos trabalhadores, pela preocupação com efeitos tóxicos na saúde e também da diminuição da exposição ambiental ao benzeno para a população em geral ${ }^{4}$.

O risco da exposição ao benzeno é amplificado quando se considera que a gasolina é um produto usado sem qualquer controle em áreas residenciais, na indústria de impressão e oficinas mecânicas como um solvente de limpeza. Nos últimos anos, a exposição ocupacional ao benzeno pela gasolina tem sido objeto de pesquisa, a fim de estabelecer a relação de causa-efeito a partir de fontes de exposição ambiental e ocupacional ${ }^{5-8}$.

O uso de biomarcadores na avaliação da exposição ocupacional às substâncias químicas constitui uma forma de detectar precocemente uma exposição excessiva do trabalhador, para prevenir a ocorrência dos efeitos adversos à saúde ${ }^{9}$. Na monitorização biológica da exposição ocupacional ao benzeno normalmente são utilizados os biomarcadores de exposição, os quais são a própria substância inalterada na urina, sangue e ar expirado, ou seus metabólitos na urina. No entanto, os estudos de avaliação da exposição ocupacional ao benzeno podem ser complementados por outros parâmetros analíticos que avaliam, além da intensidade da exposição, o efeito genotóxico ${ }^{5,10,11}$. Agentes genotóxicos, tais como o benzeno, interagem quimicamente com o material genético, resultando em adutos, modificações oxidativas ou mesmo quebras na molécula de DNA. O agente químico que promove a formação de aduto de DNA é conhecido como "DNA reativo" e, portanto, considerado como um agente genotóxico ${ }^{12-14}$.
O Teste Cometa tem larga aplicação na toxicologia para avaliar o efeito genotóxico de produtos químicos, além de ser utilizado nos estudos de biomonitoramento de trabalhadores para avaliar o risco da exposição ocupacional aos agentes potenciais ou comprovadamente cancerígenos. É considerada uma técnica versátil por sua adaptabilidade a uma variedade de tecidos, como culturas de células ou amostras biológicas ${ }^{15-18}$. O uso do Teste Cometa em células sanguíneas tem sido empregado na avaliação da exposição de trabalhadores expostos às substâncias químicas e na população em geral, como um biomarcador de efeito de substâncias químicas genotóxicas e potencialmente mutagênicas ou carcinogênicas ${ }^{19-22}$.

O objetivo deste estudo foi avaliar a exposição ocupacional ao benzeno utilizando o Teste Cometa como biomarcador de genotoxicidade em células sanguíneas de trabalhadores expostos à gasolina, e confrontar esses resultados com o ácido trans,trans-mucônico (AttM) na urina; cujo parâmetro como biomarcador de exposição correlaciona-se com a intensidade do benzeno no ar.

\section{Métodos}

Foi realizado um estudo transversal utilizando ferramentas quantitativas e avaliação das variáveis sociodemográficas e tempo de exposição.

\section{População estudada}

Foram definidos dois grupos de participantes: a) Grupo I: indivíduos expostos ocupacionalmente ao benzeno; b) Grupo II: indivíduos não expostos ocupacionalmente ao benzeno.

O Grupo I foi composto por indivíduos trabalhadores de postos de combustíveis e analistas de laboratórios de controle de qualidade de combustíveis. Os postos de revenda de combustíveis foram escolhidos por uma amostragem de conveniência, nas cidades de Ibirité e Contagem, na região metropolitana de Belo Horizonte/MG, num total de nove postos. Os analistas de combustíveis foram técnicos do Laboratório de Ensaios de Combustíveis (LEC) da Universidade Federal de Minas Gerais (UFMG), situado no campus da UFMG Pampulha. O Grupo II foi composto por indivíduos trabalhadores do setor de administração pública sem exposição ocupacional ao benzeno. Os fatores relacionados à idade, hábitos pessoais e aspectos socioeconômicos foram considerados para a seleção do respectivo grupo, de maneira que suas características fossem as mais próximas do Grupo I.

Para a seleção dos indivíduos participantes foram considerados critérios de exclusão e de elegibilidade. 
Os critérios de exclusão para os Grupos I e II foram "indivíduos fumantes" e "indivíduos menores de 18 anos". Como critérios de elegibilidade para o Grupo I, definiu-se “atividade na função por um período superior a seis meses”, e para o Grupo II "não ser exposto ocupacionalmente ao benzeno".

Todos os indivíduos que aceitaram participar do estudo e que possuíam os critérios de elegibilidade foram instruídos a preencher um questionário utilizado como instrumento para obter informações referentes aos (a) dados pessoais; (b) características e hábitos individuais; e (c) dados ocupacionais.

O estudo foi aprovado pelo Comitê de Ética em Pesquisa (COEP) da UFMG, pelo protocolo 118/1, e os dois grupos foram apresentados ao projeto e os indivíduos concordaram em participar por meio da assinatura do Termo de Consentimento Livre e Esclarecido (TCLE).

A análise estatística dos parâmetros e características da população estudada e dos parâmetros do Teste Cometa foi efetuada pelo método de Mann-Whitney. As relações entre os resultados do Teste Cometa e AttM urinário no Grupo I foram analisadas pelo coeficiente de correlação de Pearson. O nível de significância adotado para todos os testes foi de 5\%.

\section{Análise do Teste Cometa em células sanguíneas}

O Teste Cometa foi validado utilizando amostra de sangue de indivíduos não expostos ocupacionalmente a nenhuma substância química e radiação. A curva de calibração e o estudo da reprodutibilidade foram realizados utilizando diferentes doses de raios gama, cujos procedimentos analíticos asseguraram a qualidade e confiabilidade do método para que fosse aplicado em amostras dos grupos estudados. Para realização do Teste Cometa foi utilizado como amostra biológica o sangue periférico. A metodologia utilizada foi modificada a partir de procedimentos previamente descritos por Rojas et al. ${ }^{23}$, Pitozzi et al ${ }^{24}$, Hartman et al. ${ }^{25}$, de Tice et al. ${ }^{26}$ e Azqueta et al. ${ }^{27}$. O uso de controles na realização desse procedimento analítico permite verificar se o teste foi satisfatório, pois muitas substâncias podem provocar danos ao DNA e, assim, o teste pode funcionar como controle positivo. O Teste Cometa possibilita a detecção de um amplo espectro de danos no DNA com alta sensibilidade, no entanto, apresenta baixa especificidade, tendo em vista que diversas substâncias químicas podem ser associadas a esse efeito. Para realizar o controle positivo nos testes é necessário que a substância seja conhecidamente genotóxica e seja capaz de causar dano detectável pelo Teste Cometa. Entre elas está o metilmetanosulfonato (MMS), que foi utilizado em duas concentrações $(0,8 \mathrm{mM}$ e $0,4 \mathrm{mM})$ em todas as corridas do Teste Cometa durante o procedimento experimental. Durante o processo de validação, todas as amostras e controles foram realizadas em triplicatas e, para avaliar o viés da observação individual, foi utilizado um observador a mais para realização da leitura nos procedimentos de validação.

O Teste Cometa foi classificado e quantificado pelo dano ao DNA de acordo com a aparência do cometa em 5 classes, de 0 (sem cauda) a 4 (cauda total), de acordo com o nível de dano. O resultado do teste em cada amostra é expresso como "índice de dano” (ID), calculado a partir de unidades arbitrárias (UA) com um escore total de 0-400 UA, pelo somatório dos valores de 0 a 4 em 100 células escolhidas aleatoriamente.

\section{Análise do ácido trans, trans-mucônico (AttM) urinário}

A análise de AttM em amostras de urina foi realizada como descrito pelo método de Ducos ${ }^{28}$ modificado por Paula et al. ${ }^{29}$, por cromatografia líquida de alta eficiência (CLAE) com detector UV/VIS, utilizando extração em fase sólida (cartuchos de amônio quaternário). O limite de detecção (LD) e o limite de quantificação (LQ) do método utilizado é de 0,006 mg/L e $0,03 \mathrm{mg} / \mathrm{L}$, respectivamente. A curva de calibração foi construída usando soluções padrão de AttM em urina no intervalo de concentração de 0,0625-1,500 mg/L.

Os valores do AttM na urina foram corrigidos pela concentração de creatina urinária, por refletir um procedimento relevante na interpretação dos resultados dos metabólitos urinários. Essa correção é necessária, tendo em vista que a excreção dos metabólitos do benzeno pode ser alterada em presença de amostras muito concentradas (densidade $>1,030$ e creatinina $>3 \mathrm{~g} / \mathrm{L}$ ) ou diluídas (densidade $<1,010$ e creatinina $<0,5 \mathrm{~g} / \mathrm{L})^{30}$. Para realização das análises do AttM, a urina foi descartada quando o valor de creatinina na amostra apresentou-se em desacordo com essas especificações descritas pela $\mathrm{ACGIH}^{30}$.

\section{Resultados}

A população de estudo foi composta de 53 indivíduos entre as idades de 19 a 55 anos, dos quais 31 eram do sexo masculino e 22 do sexo feminino. Dos 53 indivíduos que aceitaram participar do estudo, 31 eram trabalhadores expostos e 22 eram indivíduos não expostos ocupacionalmente ao benzeno. A fim de minimizar os fatores de confusão, os grupos foram categorizados por faixa etária $(<25 ; 25$ a 35; e > 35 anos), sexo, tempo de exposição e consumo de álcool. A média (desvio padrão) da idade do Grupo I (exposto) foi de 29 (8,8) anos, variando de 23 a 55 anos. A maioria era de frentistas (58\%), homens (58\%), entre 25 e 35 anos (54,8\%), e trabalhavam há 
mais de dois anos na profissão (38,7\%). Como todos os indivíduos do Grupo I trabalhavam 8 horas por dia, esta não foi considerada uma variável a ser analisada. A idade média do Grupo II (não exposto) foi de 33 $(8,3)$, variando de 19 a 55 , sendo que a maioria eram homens (59,1\%) com idade entre 25 e 35 anos (54,5\%).

O resultado do Teste Cometa para os Grupos I e II é mostrado na Tabela 1. Os valores desse biomarcador são expressos pelo Índice de Dano (ID) e mostraram diferenças significativas $(p<0,05)$ entre os dois grupos. Os resultados das análises em relação aos fatores individuais, como sexo e idade, mostraram diferenças entre os grupos, com exceção para a categoria de idade com mais de 35 anos, cuja diferença não foi observada. O consumo de álcool entre os grupos e o tempo de exposição dentro do Grupo I não foram variáveis significativamente diferentes.

Tabela 1 Distribuição do Índice de Dano médio pelo Teste Cometa para os Grupos I (exposto) e II (não exposto), Belo Horizonte, MG, 2012

\begin{tabular}{|c|c|c|c|}
\hline Variável & $\begin{array}{l}\text { Grupo I } \\
(n=31)\end{array}$ & $\begin{array}{c}\text { Grupo II }^{\alpha} \\
(n=19)\end{array}$ & Valor de $p^{\beta}$ \\
\hline \multicolumn{4}{|l|}{ Idade } \\
\hline$<25$ & 25,5 & 12,7 & $<0,05^{*}$ \\
\hline $25-35$ & 33,7 & 16,3 & $<0,05^{*}$ \\
\hline$>35$ & 30,7 & 28,8 & $>0,05$ \\
\hline \multicolumn{4}{|l|}{ Sexo } \\
\hline Mulheres & 27 & 16,3 & $<0,05^{*}$ \\
\hline Homens & 29 & 19,3 & $<0,05^{*}$ \\
\hline \multicolumn{4}{|l|}{ Tempo de exposição } \\
\hline 6 meses a 2 anos & 29,5 & - & \multirow{2}{*}{$>0,05$} \\
\hline$>2$ anos & 26,6 & - & \\
\hline \multicolumn{4}{|l|}{ Consumo de álcool } \\
\hline Consumidores & 30,2 & 15,2 & $>0,05$ \\
\hline Não consumidores & 26,7 & 23,1 & $>0,05$ \\
\hline Média (desvio padrão) & $28,4(10,1)$ & $18,4(10,1)$ & $<0,05^{*}$ \\
\hline
\end{tabular}

${ }^{\alpha}$ Não realizado em três indivíduos

$\beta$ Teste estatístico: Mann-Whitney

*Valores estatisticamente significativos

Em relação ao tipo de profissão, verificou-se um aumento do ID em frentistas quando comparado aos analistas de combustíveis, cujos resultados são apresentados na Tabela 2. Também foram observadas diferenças significativas nos valores de ID entre frentistas e analistas, relacionados ao gênero e idade entre 25 a 35 anos.

Tabela 2 Distribuição do Índice de Dano médio pelo Teste Cometa para o Grupo I por profissão, Belo Horizonte, MG, 2012

\begin{tabular}{lccc}
\hline Variável & $\begin{array}{c}\text { Frentista } \\
(n=18)\end{array}$ & $\begin{array}{c}\text { Analista } \\
(n=13)\end{array}$ & ${\text { Valor de }{ }^{\alpha}}^{\alpha}$ \\
\hline Sexo & & & \\
$\quad$ Mulheres & 39,3 & 19,3 & $<0,05^{*}$ \\
$\quad$ Homens & 29,5 & 29,2 & $>0,05$ \\
Idade & & & \\
$\quad<25$ & 28 & 23,6 & $>0,05$ \\
$25-35$ & 34,2 & 21,5 & $<0,05^{*}$ \\
\hline Média (desvio padrão) & $32,2(10,6)$ & $23,1(6,5)$ & $<0,05^{*}$ \\
\hline
\end{tabular}

${ }^{\alpha}$ Teste estatístico: Mann-Whitney

* Valores estatisticamente significativos 
Os valores encontrados do AttM urinário para ambos os grupos são mostrados na Tabela 3. Os valores médios desse biomarcador no Grupo I apresentaram diferença significativa quando comparado com os valores do Grupo II ( $p<0,05)$. Os indivíduos com idade maior que 25 anos, e de 25 a 35 anos no grupo exposto, apresentaram níveis de AttM elevados, em comparação com indivíduos não expostos. Mulheres expostas também apresentaram aumento dos níveis de AttM. O consumo de álcool entre os grupos e o tempo de exposição dentro do Grupo I não foram variáveis significativamente diferentes.

Tabela 3 Distribuição da concentração média do ácido trans,trans-mucônico urinário para os Grupos I (exposto) e II (não exposto), Belo Horizonte, MG, 2012

\begin{tabular}{lccc}
\hline Variável & $\begin{array}{c}\text { Grupo I } \\
(n=31)\end{array}$ & $\begin{array}{c}\text { Grupo II } \\
(n=22)\end{array}$ & Valor dep $^{\alpha}$ \\
\hline Idade & 1,34 & 0,22 & $<0,05^{*}$ \\
$\quad<25$ & 1,14 & 0,37 & $<0,05^{*}$ \\
$25-35$ & 0,55 & 0,70 & $>0,05$ \\
$\quad>35$ & 1,15 & & $>0,05$ \\
Sexo & 1,11 & 0,44 & $<0,05^{*}$ \\
$\quad$ Mulheres & 1,30 & 0,44 & $>0,05$ \\
$\quad$ Homens & 0,91 & - & \\
Tempo de exposição & & & $>0,05$ \\
$\quad 6$ meses a 2 anos & 0,86 & 0,49 & $>0,05$ \\
$\quad>$ 2 anos & 1,40 & 0,40 & $<0,05^{*}$ \\
Consumo de álcool & $1,13(0,45)$ & $0,44(0,33)$ & \\
$\quad$ Consumidores & & & \\
$\quad$ Não consumidores & & & \\
\hline Média (desvio padrão) & & & \\
\hline
\end{tabular}

a Teste estatístico: Mann-Whitney

*Valores estatisticamente significativos

Frentistas apresentaram maior concentração de AttM em comparação com analistas de combustíveis, cujos resultados são mostrados na Tabela 4. Após estratificação do Grupo I, entre frentistas e analistas de combustíveis, a diferença nos valores de AttM foi observada para o gênero feminino e não diferenciado em relação à idade.

A associação entre os dois biomarcadores é demonstrada graficamente na Figura 1, cujo coeficiente de correlação linear de Pearson (r) foi 0,81 (p<0,05).

Tabela 4 Distribuição da concentração média do ácido trans,trans-mucônico urinário para o Grupo I por profissão, Belo Horizonte, MG, 2012

\begin{tabular}{lccc}
\hline Variável & $\begin{array}{c}\text { Frentista } \\
(n=18)\end{array}$ & $\begin{array}{c}\text { Analista } \\
(n=13)\end{array}$ & ${\text { Valor de }{ }^{\alpha}}^{\text {Sexo }}$ \\
$\quad$ Mulheres & 1,91 & 0,38 & $<0,05^{*}$ \\
$\quad$ Homens & 1,18 & 0,89 & $>0,05$ \\
Idade & & & \\
$\quad<25$ & 1,76 & 0,78 & $>0,05$ \\
$25-35$ & 1,34 & 0,50 & $>0,05$ \\
\hline Média (desvio padrão) & $1,38(1,18)$ & $0,61(0,35)$ & $<0,05^{*}$ \\
\hline
\end{tabular}

${ }^{\alpha}$ Teste estatístico: Mann-Whitney

* Valores estatisticamente significativos 


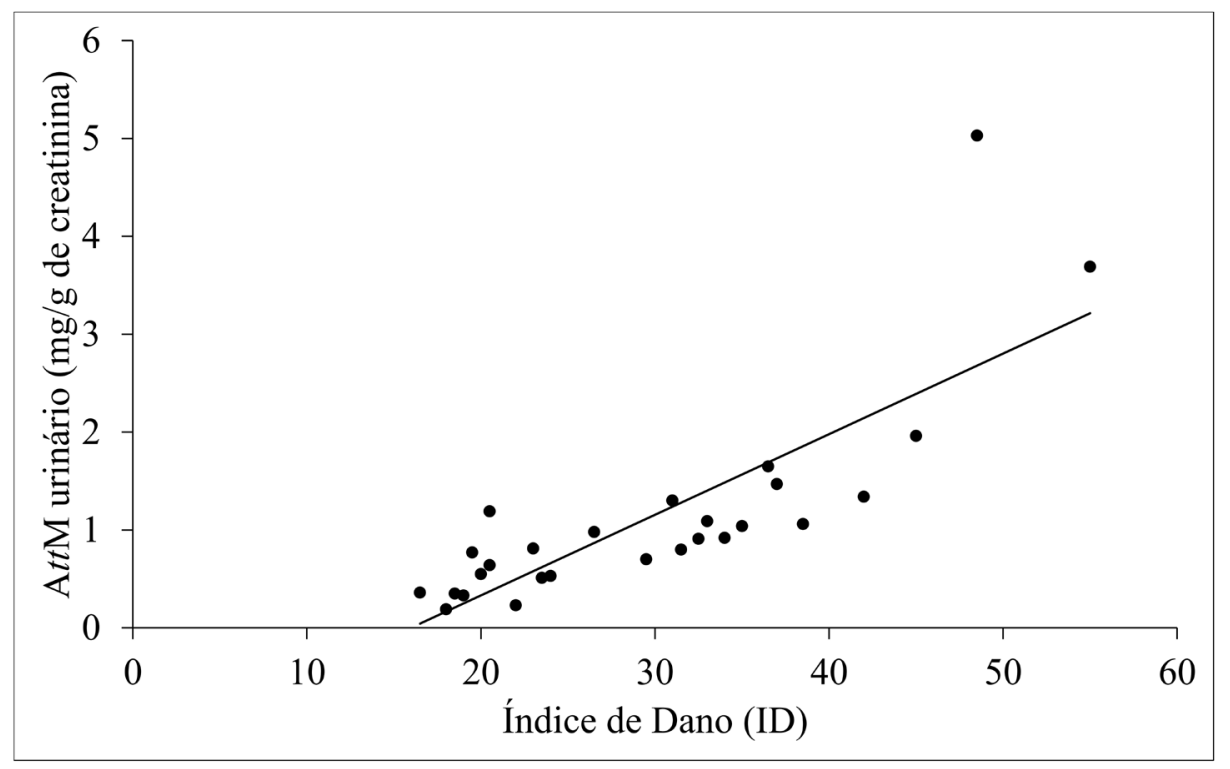

Figura 1 Relação entre a concentração de AttM urinário e Índice de Dano pelo Teste Cometa em trabalhadores expostos ao benzeno (frentistas e analistas de combustíveis). Coeficiente de correlação de Pearson $=0,81$, Belo Horizonte, MG, 2012

\section{Discussão}

Este estudo investigou o risco da exposição ocupacional ao benzeno frente aos possíveis efeitos genotóxicos em frentistas e analistas de combustíveis. Para isso, foi utilizado o Teste Cometa para determinar a extensão do dano primário ao DNA em indivíduos expostos e não expostos à gasolina, correlacionando os achados com valores de AttM urinário, que é biomarcador de dose interna do benzeno. Exposições ocupacionais a substâncias tóxicas constituem importante problema de saúde pública e este ensaio indica a possibilidade para identificar fatores de risco como uma ferramenta para caracterizar o problema, além de reforçar a necessidade de medidas de controle eficazes para proteger a saúde dos trabalhadores desse setor.

O dano ao DNA através do Teste Cometa pode ser medido manualmente ou por software. A quantificação manual foi usada para expressar os resultados, uma vez que nem todos os laboratórios têm automação. Moller et al. ${ }^{31}$ e Moller ${ }^{32}$ compararam a quantificação manual e automatizada e concluíram que havia uma relação estreita entre as duas formas, sendo considerada também a performance individual dos observadores participantes do estudo.

Os dados encontrados do Teste Cometa mostrando que o grupo exposto exibiu um grau significativamente mais elevado de danos ao DNA em linfócitos periféricos do que o grupo não exposto, seguido por um aumento da excreção urinária de AttM, foi evidenciado também em estudos relatados por outros autores $^{5,10,11,33}$.

Ao estratificar a população, para comparar os valores de ID do Teste Cometa, observamos que entre os sexos, e para idade inferior a 35 anos, a diferença entre os dois grupos é mantida, mas que para maiores de 35 anos não existe diferença de dano ao DNA para o grupo exposto e não exposto. Esse achado pode ser explicado pelo acúmulo de danos ao DNA, incluindo mutações, que ocorrem naturalmente em indivíduos mais velhos, além do pequeno número de indivíduos dessa faixa etária $(n=9)^{31}$. Esse dado é, potencialmente, uma limitação no uso do Teste Cometa, como biomarcador para avaliar a exposição ao benzeno ou a outra substância genotóxica, pois a sensibilidade pode ser afetada pela idade dos indivíduos expostos, sendo menor para grupos de indivíduos acima de 35 anos, atingindo um nível de saturação que limita a sensibilidade do Teste Cometa.

Em relação ao consumo de álcool, não foi encontrada diferença significativa nas concentrações de AttM urinário e nos valores do Teste Cometa entre os indivíduos que relataram o consumo ou não consumo de bebida alcoólica. Dado semelhante foi relatado no estudo realizado por Rekhadevi et al. ${ }^{34} \mathrm{com}$ Teste Cometa em frentistas de postos de combustíveis. Nenhuma diferença estatística foi observada no Grupo I, com relação ao tempo de exposição menor ou maior que dois anos, concordando também com dados da literatura ${ }^{11}$. 
A diferença no ID encontrado entre frentistas e analistas pode estar relacionada ao fato de que os analistas de combustíveis em geral trabalham com EPI num local com fluxo de ar controlado, diminuindo o risco da exposição pelos solventes, entre eles o benzeno. Porém, quando comparado ao controle, o grupo de analistas ainda possui um dano ao DNA relativamente mais alto e significativo.

Em relação ao biomarcador de dose interna, o ácido trans,trans-mucônico urinário, a média dos valores encontrados foi significativamente maior entre os indivíduos do Grupo I, de acordo com a norma nacional ${ }^{35}$, o que indica uma exposição ocupacional a baixas concentrações de benzeno no ar. Valores similares para frentistas também foram relatados no estudo de Costa e Costa ${ }^{36}$. No entanto, a exposição a benzeno em doses baixas não exclui o risco à saúde $^{37,38}$. De acordo com Smith et al ${ }^{38}$, o mecanismo de ação do benzeno na medula óssea leva aos efeitos tóxicos também em baixos níveis de exposição e podem aumentar gradativamente com doses crescentes e sugere que um modelo em que não exista um limite de exposição segura é o mais apropriado para a exposição ao benzeno.

No Grupo II, os valores encontrados de AttM urinário são similares a valores reportados na literatura, que foram de $<0,01-0,66 \mathrm{mg} / \mathrm{g}$ de creatinina ${ }^{28,39,40}$, considerando os diversos fatores que influenciam a concentração do AttM na urina, como tabagismo, o consumo de ácido sórbico e seus sais presentes em alguns alimentos, álcool, além de fatores individuais. Para diminuir os fatores de confusão, foram excluídos deste estudo os indivíduos fumantes e um questionário detalhado foi aplicado em ambos os grupos. O consumo de álcool não gerou diferença estatística entre os grupos, como também foi relatado por Paula et al. ${ }^{29}$. Não houve participantes do estudo que relataram o consumo excessivo de alimentos com alto teor de conservantes, como enlatados e embutidos.

Para o Grupo I, o tempo de exposição (6 meses a 2 anos e mais de 2 anos) não influenciou os valores dos biomarcadores. Foi observada uma correlação positiva entre a idade e a excreção de AttM em ambos os grupos (expostos e não expostos), demonstrando que quanto maior a idade, maior a concentração de AttM urinário, o que corrobora com o estudo realizado por Paula et al. ${ }^{29}$. Além disso, o valor médio de excreção urinária de AttM entre os frentistas foi acima daquele observado entre analistas de combustíveis, cuja diferença entre os grupos já foi mencionada para o Teste Cometa. Ao estratificar o Grupo I em relação ao gênero, foi observado que o grupo feminino apresentou maior excreção de AttM, mesma diferença observada para o Teste Cometa.
O biomonitoramento da população exposta a agentes químicos pelo Teste Cometa, nos últimos anos, tornou-se uma ferramenta importante para detectar efeitos celulares como danos do DNA ${ }^{5,11,21,17,37}$. Embora a detecção de danos no DNA, utilizando linfócitos do sangue periférico, não represente o surgimento de patologias no curto e médio prazo, os especialistas concordam que as células do sangue podem ser usadas como "células-sentinela", a fim de fornecer um sinal de detecção precoce de efeitos adversos à saúde ${ }^{41}$.

Alguns fatores individuais, como tabagismo, consumo de álcool, idade, sexo e outros são possíveis de controlar em estudos de biomonitorização, mas às vezes não é possível atribuir o dano genotóxico para um produto químico em particular. A utilização do Teste Cometa tem limitações devido à influência desses fatores de confusão. Assim, o dano ao DNA observado em nosso estudo não pode ser atribuído apenas ao benzeno, mas também a um efeito cumulativo de muitos outros compostos químicos e condições que não foram avaliadas e que podem fazer parte da vida dos participantes, no ambiente de trabalho ou não. No entanto, como neste estudo foi utilizado um grupo "controle", consideramos que há fortes evidências de que o aumento de dano ao DNA encontrado na população está ligado ao benzeno, e essa exposição ocupacional constitui um risco para a saúde.

Assim, buscou-se associar a intensidade da exposição ao benzeno expressa pelo biomarcador de dose interna (AttM urinário), com o biomarcador de genotoxicidade pelo índice de danos no DNA expresso pelo Teste Cometa. O Teste Cometa correlacionou de maneira positiva com os resultados do AttM, ou seja, quando houve uma excreção urinária maior do biomarcador, os danos ao DNA também eram maiores. Essa associação entre ambos os biomarcadores sugere que a maior exposição ocupacional está associada a um risco aumentado de dano genético entre indivíduos expostos à gasolina. $\mathrm{O}$ valor encontrado do coeficiente de correlação de 0,81 na população estudada foi superior à mesma associação descrita por Moro et $\mathrm{al}^{5}$. Apesar do Teste Cometa não ser um biomarcador de efeito específico do benzeno, sua comparação com biomarcador específico de dose interna de benzeno agrega valor à avaliação da exposição ocupacional e reconhecimento do risco.

Ao correlacionar os resultados dos biomarcadores com as variáveis de sexo e idade, a correlação positiva entre o Teste Cometa e AttM não foi mais observada, provavelmente devido aos fatores de confundimento de cada biomarcador ou pequeno número de indivíduos no estudo. 


\section{Conclusão}

O biomarcador de exposição do benzeno, ácido trans,trans-mucônico, permitiu verificar que a população exposta estudada estava em contato com a substância e que os níveis aumentados deste biomarcador para frentistas e analistas de combustível caracterizaram uma exposição ocupacional.
O Teste Cometa possibilitou diferenciar o grupo exposto mostrando-se como um biomarcador de efeito sensível, o qual é uma indicação precoce de um efeito nocivo ou uma doença.

A correlação obtida entre o biomarcador de exposição e o Teste Cometa foi forte, o que contribui para a confiabilidade do achado de que existe um risco ocupacional e genotóxico em relação à exposição ao benzeno na gasolina.

\section{Contribuições de autoria}

Todos os autores contribuíram substancialmente no delineamento, no levantamento de dados e na sua análise e interpretação, e na elaboração ou aprovação da versão final do manuscrito.

\section{Referências}

1. International Agency for Research on Cancer. World Health Organization. Monographs on the evaluation of the carcinogenic risks to humans. Chemical agents and related occupations: a review of human carcinogens, Vol. 100F. Lyon: Iarc, 2012

2. Kaiser, CR, Carlos R, Borges JL, Santos AR, Azevedo DA D'Avila LA. Quality control of gasoline by ${ }^{1} \mathrm{H}$ NMR: aromatics, olefinics, paraffinics, and oxygenated and benzene contents. Fuel. 2010;89(1):99-104.

3. Brasil. Portaria ANP $n^{\circ} 40$, de 25 de outubro de 2013. Agência Nacional do Petróleo. Estabelece as especificações para a comercialização de gasolinas automotivas em todo o território nacional e obrigações dos agentes econômicos. Diário Oficial da República Federativa do Brasil, Brasília, DF, 28 out 2011.

4. Laredo, GC, Castillo JJ, Navarrete-Bolaños J, Perez-Romo P, Lagos FA. Benzene reduction in gasoline by alkylation with olefins: comparison of Beta and MCM-22 catalysts. Appl Catal A-Gen. 2012;413/414:140-8.

5. Moro AM, Charão MF, Brucker N, Durgante J, Baierle M, Bubols G, et al. Genotoxicity and oxidative stress in gasoline station attendants. Mutat Res. 2013;754(1-2):63-70.

6. Tunsaringkarn T, Suwansaksri J, Soogarun S, Siriwong W, Rungsiyothin A, Zapuang K, et al. Genotoxic monitoring and benzene exposure assessment of gasoline station workers in metropolitan Bangkok: sister chromatid exchange (SCE) and urinary trans, trans-muconic acid (ttMA). Asian Pac J Cancer Prev. 2011;12(1):223-7.

7. Amorim LCA, Carneiro JP, Cardeal ZL. An optimized method for determination of benzene in exhaled air by gas chromatography-mass spectrometry using solid phase microextraction as a sampling technique. J Chromatogr B Analyt Technol Biomed Life Sci. 2008;865(1-2):141-6.
8. Carrieri M, Bonfiglio E, Scapellato ML, Macca I, Tranfo G, Faranda P, et al. Comparison of exposure assessment methods in occupational exposure to benzene in gasoline filling-station attendants. Toxicol Lett. 2006;162(2-3):146-52.

9. Amorim LCA. O Uso dos biomarcadores na avaliação da exposição ocupacional a substâncias químicas. Rev Bras Med Trab. 2003;1(2):124-2.

10. Keretetse GS, Laubscher PJ, Du Plessis JL, Pretorius PJ, Van Der Westhuizen FH, Van Deventer E, et al. DNA damage and repair detected by the comet assay in lymphocytes of African petrol attendants: a pilot study. Ann Occup Hyg. 2008;52(7):653-62.

11. Pandey AK, Bajpayee M, Parmar D, Alok K, Kumar R, Rastogi SK, et al. Multipronged evaluation of genotoxicity in Indian petrol-pump workers. Environ Mol Mutagen. 2008;49(9):695-707.

12. Silva J, Heuser V, Andrade V. Biomonitoramento ambiental. In: Silva J, Erdtmann B, Henriques JAP. Genética Toxicológica. Porto Alegre: Alcance; 2003. p. 167-178.

13. Hayes RB, Songnian Y, Dosemeci M, Linet M. Benzene and lymphohematopoietic malignancies in humans. Am J Ind Med. 2001;40(2):117-26.

14. Wang L, He X, Bi Y, Ma Q. Stem cell and benzeneinduced malignancy and hematotoxicity. Chem Res Toxicol. 2012;25(7):1303-15.

15. Collins AR, Oscoz AA, Brunborg G, Gavião I, Giovannelli L, Kruzewski M, et al. The comet assay: topical issues. Mutagenesis. 2008;23(3):1-9.

16. Ramos AA, Lima CF, Pereira ML, FernandesFerreira M, Pereira-Wilson C. Antigenotoxic effects of quercetin, rutin and ursolic acid on HepG2 cells: evaluation by the comet assay. Toxicol Lett. 2008;177(1):66-73.

17. Wang A, Robertson JL, Holladay SD, Tennant AH, Lengi AJ, Ansar Ahmed S, et al. Measurement of DNA damage in rat urinary bladder transitional cells: improved selective harvest of transitional cells 
and detailed Comet assay protocols. Mutat Res. 2007;634(1-2):51-9.

18. Roma-Torres J, Teixeira JP, Silva S, Laffon B, Cunha LM, Mendez J, et al. Evaluation of genotoxicity in a group of workers from a petroleum refinery aromatics plant. Mutat Res. 2006;604(1-2):19-27.

19. Coronas MV, Horn RC, Ducatti A, Rocha JAV, Vargas VMF. Mutagenic activity of airborne particulate matter in petrochemical industrial area. Mutat Res. 2008;650(2):196-201.

20. Faust F, Kassie F, Knasmüller S, Kevekordes S, Mersch-Sundermann V. Use of primary blood cells for the assessment of exposure to occupational genotoxicants in human biomonitoring studies. Toxicology. 2004;198(1-3):341-50.

21. Grover P, Rekhadevi PV, Danadevi K, Vuyyuri SB, Mahboob M, Rahman MF. Genotoxicity evaluation in workers occupationally exposed to lead. Int J Hyg Environ Health..2010;213(2):99-106.

22. Kapka-Skrzypczak L, Cyranka M, Skrzypczak M, Kruszewski M. Biomonitoring and biomarkers of organophosphate pesticides exposure - state of the art. Ann Agric Environ Med. 2011;18(2):294-303.

23. Rojas E, Lopez MC, Valverde M. Single cell gel electrophoresis assay: methodology and applications. J Chromatogr B Biomed Sci Appl. 1999;722(1-2):225-54.

24. Pitozzi, V., Pallotta, S., Balzi, M., Bucciolini, M., Becciolini, A., Dolara, P., Giovannelli, L. Calibration of the comet assay for the measurement of DNA damage in mammalian cells. Free Radic Res. 2006;40(11):1149-54.

25. Hartmann A, Agurell E, Beevers C, Brendler-Schwaab S, Burlinson B, Clay P, et al. Recommendations for conducting the in vivo alkaline Comet assay. Mutagenesis.2003;18(1):45-51.

26. Tice RR, Agurell E, Anderson D, Burlinson B, Hartmann A, Kobayashi H, et al. Single cell gel/ comet assay: guidelines for in vitro and in vivo genetic toxicology testing. Environ Mol Mutagen. 2000;35(3):206-21.

27. Azqueta A, Gutzkow KB, Brunborg G, Collins AR. Towards a more reliable comet assay: optimising agarose concentration, unwinding time and electrophoresis conditions. Mutat Res. 2011;724(1-2):41-5.

28. Ducos P, Gaudin R, Bel J, Marie C, Francin JM, Robert A, et al. Trans,trans-muconic acid, a reliable biological indicator for the detection of individual benzene exposure down to the ppm level. Int Arch Occup Environ Health. 1992;64(5):309-13.

29. Paula FCS, Silveira JN, Junqueira JG, Leite EMA. Avaliação do ácido trans, trans-mucônico urinário como bioindicador de exposição ao benzeno. Rev Saúde Pub. 2003;37:780-5.
30. American Conference of Governmental and Industrial Hygienists. Guide for evaluation and control of workplace exposures to chemical substances and physical agents (TLVs) and Biological Exposure Indices (BEIs). $8^{\text {th }}$ ed. California: Signature Publications; 2016. p. 272. ID: 0116.

31. Moller P, Friis G, Christensen PH, Risom L, Plesner G, Kjaersgaard J, et al. Intra-laboratory comet assay sample scoring exercise for determination of formamidopyrimidine DNA glycosylase sites in human mononuclear blood cell DNA. Free Radic Res. 2004;38(11):1207-14.

32. Moller P. The alkaline comet assay: towards validation in biomonitoring of DNA damaging exposures. Basic Clin Pharmacol Toxicol. 2006;98:336-45.

33. Andreoli C, Leopardi P, Crebelli R. Detection of DNA damage in human lymphocytes by alkaline single cell gel electrophoresis after exposure to benzene or benzene metabolites. Mutt Res. 1997;377(1):95-104.

34. Rekhadevi PV, Rahman MF, Mahboob M, Grover P. Genotoxicity in filling station attendants exposed to petroleum hydrocarbons. Ann Occup Hyg. 2010;54(8):944-54.

35. Brasil. Ministério do Trabalho e Emprego. Portaria $\mathrm{n}^{\mathrm{o}} 34$, de 20 de dezembro de 2001. Publica protocolo visando determinar os procedimentos para a utilização de indicador biológico de exposição ocupacional ao benzeno. Diário Oficial da União, Brasília, DF, 27 dez 2001.

36. Costa MAF, Costa MFB. Benzeno: uma questão de saúde pública. Interciencia. 2002;27(4):201-4.

37. Fracasso ME, Doria D, Bartolucci GB, Carrieri M, Lovreglio P, Ballini A, et al. Low air levels of benzene: correlation between biomarkers of exposure and genotoxic effects. Toxicol Lett. 2010;192(1):22-8.

38. Smith MT, Zhang L, McHale CM, Skibola, CF, Rappaport SM. Benzene, the exposure and future investigations of leukemia etiology. Chem Biol Interact. 2011;192(1-2):155-9.

39. Gobba F, Rovesti S, Borella P, Vivoli R, Caselgrandi E, Vivoli G. Inter-individual variability of benzene metabolism to trans,trans-muconic acid and its implications in the biological monitoring of occupational exposure. Sci Total Environ. 1997;199(1-2):41-9.

40. Boogaard PJ, Van Sittert NJ. Biological monitoring of exposure to benzene: a comparison between S-phenylmercapturic acid, trans,trans-muconic acid, and phenol. Occup Environ Med. 1995;52(9):611-6.

41. Anderson D, Yu TW, Mcgregor DB. Comet assay responses as indicators of carcinogen exposure. Mutagenesis. 1998;13:539-55. 